\title{
Work engagement and perceived customer value, the mediating role of meaningfulness through work
}

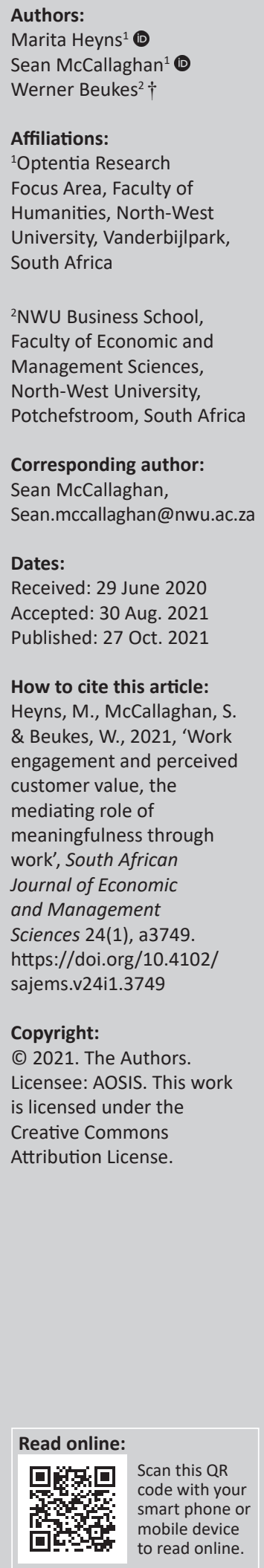

Background: Work engagement is considered an important contributor towards the success of any organisation, while finding meaning in work has been proven to enhance productivity and, ultimately, assists in improving the bottom line of an organisation.

Aim: The aim of the study is to examine work engagement and meaningfulness through work and at the workplace, and how these factors impact on perceived customer value. More specifically, the researchers were interested in whether meaningfulness could mediate the relationship between work engagement and perceived customer value.

Setting: Data were collected from employees at a large South African manufacturing organisation.

Methods: Respondents from a manufacturing organisation in South Africa participated in the quantitative cross-sectional study $(N=152)$. They completed previously validated questionnaires to assess work engagement, meaningfulness through work and perceived customer value from an employee perspective. (Males $=52.21 \%$; Working less than five years in the industry $=54.61 \%$; Non-management $=50 \%$ ).

Results: Correlation results indicate that features of engagement, meaningfulness through work and perceived customer value were positively associated. A simple mediation model indicates that meaning could be considered a mediator in the relationship between work engagement and perceived customer value.

Conclusion: Study results indicate that work engagement was not sufficient to improve perceived customer value and that finding meaning in and through work was also required.

Keywords: perceived customer value; employee engagement; manufacturing organisation; meaningfulness through and in work; South Africa.

\section{Introduction}

A competitive advantage imparted by work engagement is gaining momentum as a preferred topic amongst change and human-resource practitioners (Joshi \& Sodhi 2011). Senior leaders further agree that employees' engagement is crucial to achieving results in business. The significance of the financial implications of engagement has been quantified to the extent that a 5\% increase in engagement leads to a 3\% increase in revenue growth (AON Hewitt 2015). According to Watson (2012), research also confirmed that high levels of engagement are associated with better operational and financial results. Engagement is considered, by Schaufeli (2014), as the relationship employees have with their work and their organisation. Employees who are physically, cognitively and emotionally engaged in their work, ensure that companies are more productive and profitable (AON Hewitt 2015). However, the opposite is also a reality. Evidence suggests that employees who are not fully engaged, do not focus on customers' needs (Kumar \& Pansari 2016).

Arguably, scholars suggest that work engagement may have an impact on perceived customer value (Barnes, Ponder \& Hopkins 2015; Fairlie 2011). Employees who experience higher levels of engagement are more likely to deliver positive customer experiences, create customer value, and, thereby, contribute towards something meaningful which adds societal value (Fairlie, 2011). Although it is evident that research in meta-analytic publications on perceived customer value, from a consumer perspective, is abundant (Barari et al. 2021, Leuschner, Charvet \& Rogers 2013), it seems that research on perceived customer value, from an employee perspective, is limited (Barnes et al. 2015). Perceived customer value or perceived customer delight from an employee perspective is considered to be the emotions and behaviour an employee might experience from providing value to a client or consumer (Barnes et al. 2015). Additionally, Slater (1997) observed

$\dagger, 1983-2020$. 
that perceived customer value, in which an employee forms a link between the producer and the value created, is justified by the price performance relationship. Research further indicates that perceived customer value or delight, from an employee perspective, may also be associated with job satisfaction, positive affect, affective commitment and positive behaviour such as in external representation, internal influence and service delivery (Barnes et al. 2015).

With regards to meaningfulness through, and in work, and work engagement, previous research found that these factors are positively associated (May, Gilson \& Harter 2004). This may be attributed to an increase in employees' drive towards self-actualisation, which closely correlates with a higher purpose, a sense of work and life accomplishment and with contributing positively to society (Fairlie 2011). Scholars agree that the antecedents of meaningfulness at the workplace may be psychological meaningfulness, psychological safety and psychological availability (May et al. 2004). According to May et al. (2004), psychological meaningfulness is value assigned to a work goal or objective which is evaluated in relation to a person's own values and morals. In terms of psychological safety, Kahn (1990:708) regards psychological safety 'as feeling able to show and employ oneself without fear of negative consequences to self-image, status or career'. Psychological availability refers to employees' readiness, or confidence, to fully engage in their role, despite being involved in other life experiences (May et al. 2004). Scholars further agree that meaningfulness through work contributes to and/or benefits society as a whole (D'Enbeau \& Buzzanell 2013). This is supported by the view of Fairlie (2011) who notes that employees experience increased levels of engagement on which work is meaningful, interesting and that contributes to society.

Meaningfulness in work has also been associated with multiple individual outcomes. These outcomes include feelings of accomplishment, fulfilment, and satisfaction (Steger \& Dik 2010). Finding meaning in and through work has similarly been associated with a desire for increased autonomy and the aspiration to contribute to the organisation (Geldenhuys, Laba \& Venter 2014). From an organisational perspective, this kind of meaning has been associated with improved productivity (Holbeche \& Springett 2004). This notion of Holbeche and Springett (2004) is important as increased perceived customer value has been closely related with productivity (Anderson, Fornel \& Rust 1997). Through a process of enhanced sense-making, meaningfulness could stretch benefits beyond the organisation, and research has shown that individuals would also exhibit improved behaviour associated with corporate social responsibility (Aguinis \& Glavas 2019). Therefore, it is evident that the benefits of meaningfulness through work could also extend beyond the organisation.

Literature shows, conceptually, that work engagement has an impact on meaningfulness (Fairlie 2011; May et al. 2004), as well as on perceived customer value. However, it seems that literature is silent on the effect of meaningfulness on the relationship between work engagement and perceived customer value, if these variables are entered into the relationship simultaneously. Consequently, the aim in the present study is to test a mediation model in which work engagement is considered the independent variable, meaningfulness through work as the proposed mediator, and perceived customer value as the dependent variable. Figure 1 below shows the proposed mediation model.

\section{Work engagement and its features}

Schaufeli (2014) notes that work engagement and employee engagement are used interchangeably; however, work engagement refers to the relationship between the employees and their work, while employee engagement refers to the relationship between employees and the organisation. In the context of this study, the focus is on work engagement.

According to Schaufeli, Bakker and Salanova (2006), work engagement is a positive, fulfilling work-related state of mind that is characterised by vigour, dedication and absorption. Consequently, work engagement may be assessed by examining vigour, dedication and absorption (Schaufeli et al. 2006). Vigour is defined as high energy levels, tenacity in difficult assignments and the desire to master certain skills and tasks. Dedication is the feeling of inspiration, accompanied by satisfaction, and of work being important and challenging to the individual. Absorption is being engrossed in one's work, accompanied by happiness and deep levels of attentiveness. Employees, who experience a state of work engagement, have an effectual vital association with their work and feel that they meet the requirements of their role (Schaufeli et al. 2006).

\section{Work engagement, meaningfulness at work and the importance for perceived customer value}

Work engagement is becoming more important for business leaders and managers, due to its relevance to service-related outcomes; this is mainly due to work engagement being predictive in relation to performance (Barnes et al. 2014). Not only does work engagement predict performance accurately, but it has also been associated with finding meaning in work (Hoole \& Bonnema 2015). Additionally, researchers are now suggesting that complete work engagement could also lead to meaningfulness at the work place (Hager 2018). Meaningfulness is influenced by job enrichment, work-role fit and co-worker relations (May et al. 2004). Job enrichment has an influence on the degree of meaningfulness experienced through work, while meaningfulness has an even larger impact when

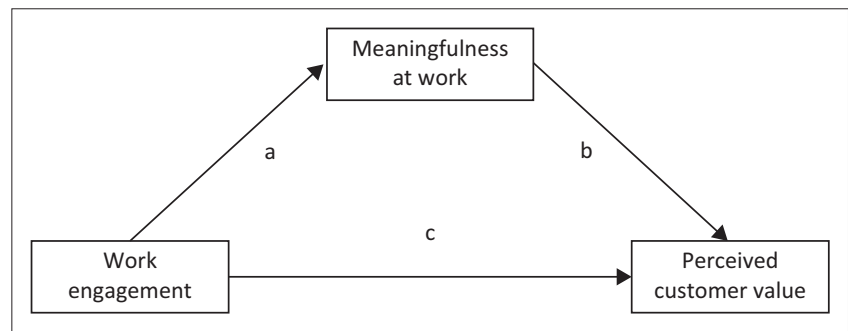

FIGURE 1: Proposed mediation model, work engagement, meaningfulness at work and perceived customer value. 
the individual has sound working relationships with co-workers (May et al. 2004). In terms of the current research, literature shows that when employees experience meaningfulness at the workplace through job design, it may influence employees' interaction with clients and consumers (Kahn 1990). Finding meaning in one's work has also been associated with improved job performance (Rodell 2013). Consequently, if employees are not fully engaged, they do not focus on customers' needs. There is potential benefit in each interaction of employees with customers, which may have an impact on the customer's perception of the organisation and brand image; if employees are disengaged it would probably have a negative impact on organisational performance (Kumar \& Pansari 2016).

\section{Work engagement, meaningfulness through work and perceived customer value in the South African environment}

Work engagement in a South African environment was found to be associated with psychological meaningfulness (Geldenhuys et al. 2014; Van Zyl, Deacon \& Rothmann 2010). According to Geldenhuys et al. (2014), meaningful work is especially important in the South African environment, as this results in employees being committed to their organisations. Previous South African research found that work engagement and meaningfulness were associated with satisfaction in life (Williamson \& Geldenhuys 2014). Although the relationship between work engagement and meaningfulness is welldocumented from a South African perspective, the indirect effect meaning might have on the relationship between work engagement and perceived customer value in a South African environment remains uncertain.

Further, there seems to be a research opportunity for a more thorough examination of the relationship between work engagement and performance (Christian \& Slaughter 2007). In the case of this study, the performance variable is perceived customer value. Perceived customer value has been associated with customer satisfaction (Han \& Xie 2019) and sales performance (Chakrabarty, Brown \& Widing 2010). From a South African perspective, perceived customer value has also been associated with consumer satisfaction (Mbango \& Toerien 2019).

\section{Goals of the study}

Taking into consideration the preceding facts and information obtained from literature, the primary objective of the present study is to determine the nature of the relationship between work engagement, meaningfulness through work and perceived customer value. More specifically, the question we sought to answer is: Can meaningfulness be considered a mediator in the relationship between work engagement and perceived customer value?

\section{Method}

A quantitative research approach was followed. A nonprobability convenience sampling strategy was used to collect data from the employees $(N=152)$ of a company operating in the manufacturing sector for household plumbing materials. The sample was dominated by the male group (52.21\%), while $54.61 \%$ of the respondents indicated that they had been working in the industry for less than five years. Results also show that $50 \%$ of the sample group considered themselves not part of management, and $34.21 \%$ of respondents indicated that they regard themselves as skilled and academically qualified. The average age of respondents was 40.67 years.

\section{Measurements}

The measuring instrument involved two steps. In the first step, biographical information from respondents was collected, while views on work engagement, meaningfulness through work and on perceptions of customer value were collected in the second step.

\section{The Utrecht Work Engagement Scale (nine items)}

The work engagement variable was assessed, using the Utrecht Work Engagement Scale (UWES-9: Schaufeli et al. 2006). The shortened nine-item scale assesses work engagement through vigour (3 items), dedication (3 items) and absorption (3 items). The UWES-9 makes use of a 7-point Likert scale on which 0 indicates Never and 6 Always. A typical item from the UWES-9 would be: 'I am proud of the work that I do'. The UWES-9 was found to be a reliable instrument for work engagement in the present study $(\alpha=0.91 ; r=0.50)$.

\section{Meaningfulness at Work Scale}

The meaningfulness variable was assessed by the Meaningfulness at Work Scale (MAW: May et al. 2004). The 14-item scale measures meaningfulness through work with validated subcomponents, namely psychological meaningfulness (6 items), psychological safety (3 items) and psychological availability (5 items). The MAW makes use of a 6-point Likert scale in which 1 means Never and 6 Every day. A typical item would be: 'That your work makes a difference to the world'? The MAW demonstrated adequate reliability in the present study $(\alpha=0.86 ; r=0.36)$.

\section{Perceived Customer Value Scale}

The perceived customer value was measured, employing the Perceived Customer Value Scale (PCS: Leroi-Werelds et al. 2014). The one-dimensional scale assesses perceived customer value against five items. The PCS makes use of a 9-point Likert scale in which 1 means Extremely unimportant and 9 Extremely important. A typical item would be: 'The company prices appear to be a bargain'. The PCS demonstrated satisfactory internal consistency $(\alpha=0.64 ; r=0.26)$.

\section{Procedure}

The holding company from the manufacturing sector was requested to participate in the research by contacting their executive management and human-resource departments. An introductory meeting was held with representatives from the various human-resource departments to explain the rationale 
behind and focus of the study. A covering letter, as well as a questionnaire, were distributed to sampled employees, via email, through their human-resource departments. Respondents were given 30 days to complete the questionnaire and were reminded once a week. In the covering section of the questionnaire, ethical considerations were addressed by assuring participants of confidentiality and non-prejudice. All the participants were free to voluntarily participate and were not coerced in any way. Theholding company from themanufacturing sector granted permission to conduct the research.

\section{Statistical analysis}

Data was cleaned, captured and analysed with the Statistical Package for Social Sciences (SPSS) and Analysis of a Moment Structure (AMOS), version 26 (IBM Corp 2019). Descriptive statistics (means and standard deviations) were calculated in order to determine central tendencies for work engagement, meaningfulness at work and perceived customer value. Internal consistency was determined by calculating Cronbach's alphas $(\alpha)$ and inter-item correlations $(r)$. Cronbach's alpha threshold was set at a moderate level ( $\alpha=0.60$; Robinson, Shaver \& Wrightsman 1991) while inter-item correlation was considered sufficient ( $r=0.20-0.40$; Pallant 2007).

An exploratory factor analysis (EFA) was conducted for individual variables in order to assess the internal structure. Principal component analysis was used as the extraction method. Examinations included the Kaiser-Meyer-Olkin (KMO) measure of sampling adequacy and Bartlett's test of sphericity. According to Field (2009), KMO values should be as close as possible to 1 and Bartlett's test of sphericity should be significant, while eigenvalues larger than 1.00 were used as criteria for factor selection. The minimum threshold set for factor loadings was considered adequate at 0.40 (Hinkin 1998).

Once reliability and the internal structure were confirmed, the work engagement, meaningfulness through work and perceived customer value variables were subjected to a confirmatory factor analysis (CFA) by making use of AMOS. We considered the Root Mean Square Error of Approximation (RMSEA) and relative/normed chi-square $\left(\chi^{2} / \mathrm{df}\right)$ as absolute fit-indices, while incremental fit-indices included the Tucker-
Lewis Index (TLI) and Comparative Fit Index (CFI). The cutoff criteria for adequate CFA were considered to be: RMSEA $<0.08$ (Van de Schoot, Lugtig \& Hox 2012), $\chi^{2} / \mathrm{df}<2.0$ (Tabachnick \& Fidell 2007) CFI and TLI $>0.90$ (Wang \& Wang 2012).

Spearman's correlations were calculated in order to determine the type and nature of the relationships between the variables under investigation. Correlations were firstly analysed for statistical significance $(p<0.05)$, and additionally assessed for practical significance. Practical significance was considered at $r \geq 0.10$, medium effect at $r \geq 0.30$, and large effect at $r \geq 0.50$ (Cohen 1988). Additionally, the final model was tested for multicollinearity. Thresholds for multicollinearity was set at 4.00 for variance inflation factors (VIF), and not less than 0.20 for tolerance (Hair et al. 2010). Direct and indirect effects were assessed by computing a simple mediation model with PROCESS (Hayes 2017), which is installed in SPSS. Direct effects were considered significant at $p<0.05$, while indirect effects were considered significant if the lower-level confidence interval (LLCI) and upper-level confidence interval (ULCI) excluded zero (Zhao, Lynch \& Chen 2010).

\section{Descriptive, reliability and correlation results}

Table 1 shows the results obtained from the descriptive, reliability and correlation analyses. According to Table 1, all variables, except psychological safety met the set of minimum criteria for internal consistency. However, Pallant (2007) indicates that scales with less than 10 items may present as problematic, so low Cronbach's alphas and, therefore, inter-item correlations should also be considered. Psychological safety was assessed against only three scale items. The inter-item correlation for psychological safety $(r=$ 0.25 ) was considered adequate and the variable was deemed reliable.

Closer examination of the mean and standard deviation scores revealed that all variables were within each scale's 'positive' range. Therefore, we are able to confirm that, according to the respondents, there was a conducive level of work engagement; they experienced meaningfulness at the workplace and had a positive perspective on providing customer value.

TABLE 1: Descriptive, reliability and correlation results.

\begin{tabular}{|c|c|c|c|c|c|c|c|c|c|c|c|c|c|}
\hline Number & Variable & Mean & SD & $\alpha(r)$ & 1 & 2 & 3 & 4 & 5 & 6 & 7 & 8 & 9 \\
\hline 1 & Work engagement & 4.57 & 1.02 & $0.91(0.50)$ & 1 & - & - & - & - & - & - & - & - \\
\hline 2 & Vigour & 4.36 & 1.28 & $0.85(0.66)$ & $0.90 *$ & 1 & - & - & - & - & - & - & - \\
\hline 3 & Dedication & 4.92 & 1.11 & $0.82(0.61)$ & $0.89 *$ & $0.71 *$ & 1 & - & - & - & - & - & - \\
\hline 4 & Absorption & 4.43 & 1.06 & $0.67(0.40)$ & $0.87^{*}$ & $0.67 *$ & $0.68 *$ & 1 & - & - & - & - & - \\
\hline 5 & Meaningfulness at work & 4.37 & 0.57 & $0.86(0.36)$ & $0.65^{*}$ & $0.65 *$ & $0.57 *$ & $0.50 *$ & 1 & - & - & - & - \\
\hline 6 & $\begin{array}{l}\text { Psychological } \\
\text { meaningfulness }\end{array}$ & 4.51 & 0.75 & $0.92(0.65)$ & $0.72 *$ & $0.66^{*}$ & $0.69 *$ & $0.57 *$ & $0.87^{*}$ & 1 & - & - & - \\
\hline 7 & Psychological safety & 3.68 & 0.97 & $0.51(0.25)$ & $0.27 *$ & $0.35 *$ & $0.19 *$ & $0.16 *$ & $0.65^{*}$ & $0.30 *$ & 1 & - & - \\
\hline 8 & Psychological availability & 4.60 & 0.56 & $0.81(0.48)$ & $0.41 *$ & $0.44 *$ & $0.33^{*}$ & $0.33^{*}$ & $0.79 *$ & $0.56^{*}$ & $0.35^{*}$ & 1 & - \\
\hline 9 & Perceived customer value & 6.38 & 1.15 & $0.64(0.26)$ & $0.29 *$ & $0.26 *$ & $0.32 *$ & $0.19 *$ & $0.35 *$ & $0.32 *$ & $0.25 *$ & $0.23 *$ & 1 \\
\hline
\end{tabular}

*Note: Correlation is significant at the 0.05 level (2-tailed).

Results were interpreted as: $0.1=$ small effect; $0.3=$ medium effect; and $0.5=$ large effect .

$r=$ inter-item correlations 
With regard to the relationships between the variables under investigation, the results from the Spearman's rank order correlations demonstrated that work engagement, meaningfulness and perceived customer value had a significant positive relationship. A strong positive relationship $(r=0.65 ; p<0.05$; large effect) existed between work engagement and meaningfulness. In reality, this result translates into a situation where respondents, who reported positive levels of work engagement, would also be inclined to report high levels of meaningfulness. In terms of the relationship between meaningfulness and perceived customer value, the result was a moderate positive relationship ( $r=0.35 ; p=0.05$; medium effect). This result suggests that positive levels of meaningfulness will also be associated with positive levels of perceived customer value. The correlation calculation between work engagement and perceived customer value demonstrated a positive result $(r=0.29 ; p<0.05$; small effect) as well. Although interpreted as a small effect, this result implies that respondents, who reported conducive levels of work engagement, were also likely to report conducive levels of perceived customer value.

Concerns with regard to potential multicollinearity were dismissed, due to results obtained from VIF and tolerance computations. Scores for VIF ranged from 2.74 to 1.56, and for tolerance from 0.37 to 0.63. Consequently, work engagement, meaningfulness and perceived customer value may be applied independently with confidence in the simple mediation model.

\section{Exploratory factor analysis}

An exploratory factor analysis (EFA) was conducted on each individual variable in order to examine the structure. The examinations of eigenvalues and scree plots confirmed the individual factors for each variable. For vigour, the first factor extracted, explained $73.72 \%$ of the variance with an eigenvalue of 2.21. Factor loadings ranged from 0.75 to 0.77 for vigour $(\mathrm{KMO}=0.72$; Bartlett's test of sphericity $=p<0.01)$. With regard to dedication, the first factor extracted, explained $74.33 \%$ of the variance with an eigenvalue of 2.23 and factor loadings ranging from 0.67 to $0.90(\mathrm{KMO}=0.70$, Bartlett's test of sphericity $=p<0.01$ ). For absorption, the first factor extracted, explained $63.57 \%$ of the variance, with factor loadings ranging from 0.67 to $0.72(\mathrm{KMO}=0.70$; Bartlett's test of sphericity $=p<0.01$ ). For perceived customer value, the single factor extracted, explained $60.03 \%$ of the variance with an eigenvalue of 2.40. Factor loadings for perceived customer value ranged from 0.56 to $0.92(\mathrm{KMO}=0.72$; Bartlett's test of sphericity $=p<0.01)$.

For psychological meaningfulness, the first factor extracted during the EFA explained $70.90 \%$ of the variance with an eigenvalue of 4.26. Factor loadings ranged from 0.69 to 0.89 for psychological meaningfulness $(\mathrm{KMO}=0.85$; Bartlett's test of sphericity $=p<0.01$ ). The single factor extracted for psychological safety explained $51.00 \%$ of the variance with an eigenvalue of 1.52. Factor loadings ranged from 0.40 to 0.62 for psychological safety $(\mathrm{KMO}=0.60$; Bartlett's test of sphericity $=p<0.01)$. In terms of psychological availability, the single factor extracted, explained 58.81 of the variance with an eigenvalue of 2.94. Factor loadings for psychological availability ranged from 0.63 to $0.86(\mathrm{KMO}=0.81$; Bartlett's test of sphericity $=p<0.01$ ).

\section{Confirmatory factor analysis}

A latent variable model was constructed in AMOS in order to conduct the CFA. Work engagement was considered by assessing vigour, dedication and absorption, while perceived customer value was considered as a one-dimensional variable. Meaningfulness at work was considered by assessing psychological meaningfulness, psychological safety and psychological availability. The model demonstrated adequate fit $\left(\chi^{2}=448 ; d f=289 ; p<0.001 ; \chi^{2} / d f=1690 ; T L I=0.90 ; C F I=\right.$ 0.91 ; RMSEA $=0.068$ ). Based on the results obtained from the CFA, validity for the present study was deemed acceptable.

\section{Simple mediation model}

The results of the simple mediation model are illustrated in Table 2. Work engagement was considered the independent variable, perceived customer value the dependent variable and meaningfulness the proposed mediator.

According to the results of the standardised regression coefficients, the first regression (1) in which work engagement was considered the independent variable and the proposed mediator, meaningfulness at work, the dependent variable, yielded a significant result $(b=0.36, t(150)=10.41, p<0.01)$. The second regression (2) in which the proposed mediator, meaningfulness, was considered the independent variable and perceived customer value the dependent variable, also yielded a significant result $(b=0.57, t(149)=2.83, p<0.01)$. The final regression (3) in which work engagement was considered the independent variable and perceived customer value the dependent variable, did not yield a significant result $(b=0.12, t(149)=1.05, p=0.29)$. The indirect effect of meaningfulness at the workplace on the relationship between work engagement and perceived customer value was also significant $(b=0.20, S E=0.08, L L C I=0.06$ and $U L C I=0.36)$. The indirect effect from the bootstrap analysis with a $95 \%$ confidence interval did not include zero; therefore, $(a x b)$ is significant (Zhao et al. 2010). Consequently, meaningfulness may be considered a mediator for the relationship between

TABLE 2: Standardised regression coefficients: work engagement, meaningfulness at work and perceived customer value.

\begin{tabular}{|c|c|c|c|c|}
\hline \multirow[t]{2}{*}{ Variable } & \multirow[t]{2}{*}{ Estimate } & \multirow[t]{2}{*}{ SE } & \multicolumn{2}{|c|}{$\begin{array}{c}\text { Bootstrapping BC } \\
95 \% \mathrm{Cl} \\
\end{array}$} \\
\hline & & & Lower & Uppe \\
\hline $\begin{array}{l}\text { Work engagement } \rightarrow \\
\text { Meaningfulness at work (a) }\end{array}$ & $0.36 *$ & 0.03 & 0.29 & 0.43 \\
\hline $\begin{array}{l}\text { Meaningfulness at work } \rightarrow \\
\text { Perceived customer value (b) }\end{array}$ & $0.57 *$ & 0.20 & 0.17 & 0.97 \\
\hline $\begin{array}{l}\text { Work engagement } \rightarrow \text { Perceived } \\
\text { customer value (c) }\end{array}$ & 0.12 & 0.11 & -0.10 & 0.34 \\
\hline $\begin{array}{l}\text { Work engagement } \rightarrow \text { Perceived } \\
\text { customer value via } \\
\text { Meaningfulness at work }\end{array}$ & $0.20 *$ & 0.08 & 0.06 & 0.36 \\
\hline
\end{tabular}


work engagement and perceived customer value. The results for the simple mediation model are shown in Figure 2 below.

\section{Discussion}

The aim of the study is assessing the indirect effect of work engagement on perceived customer value, via meaningfulness at work. The purpose was further to examine the relationships between work engagement, meaningfulness at work and perceived customer value, as well as the direct effects.

The primary objective was achieved with evidence from a simple mediation model indicating an indirect effect of meaningfulness on the relationship between work engagement and perceived customer value. This result suggests that work engagement is not adequate on its own to have an impact on perceived customer value; what is also required is an improvement in the meaningfulness through work. Not only does this result confirm the present study's conceptual model, it also confirms the importance of finding meaning for individuals as suggested by D'Enbeau and Buzzanell (2013).

Our results further indicate that work engagement could predict meaningfulness by suggesting that an improvement in work engagement may also result in an improvement of meaningfulness at the workplace. This finding confirms the proposed model of Hager (2018), who suggested that work engagement could impact on meaningfulness. Hager's study also found evidence that meaningfulness could influence perceived customer value. Consequently, enhancing meaningfulness should improve perceived customer value; therefore, confirming the conceptual position of the present study that meaningful work results in perceived customer value.

In the present study statistical evidence was not found that an improvement in work engagement results in greater perceived customer value. Previous research suggests that work engagement may indeed be associated with a competitive advantage (Joshi \& Sodhi 2011) and that disengaged workers probably did not really consider the needs of their consumers (Kumar \& Pansari 2016). The contradictory results may require further examination, as the current study found proof that respondents from the manufacturing organisation demonstrated signs of employee engagement.

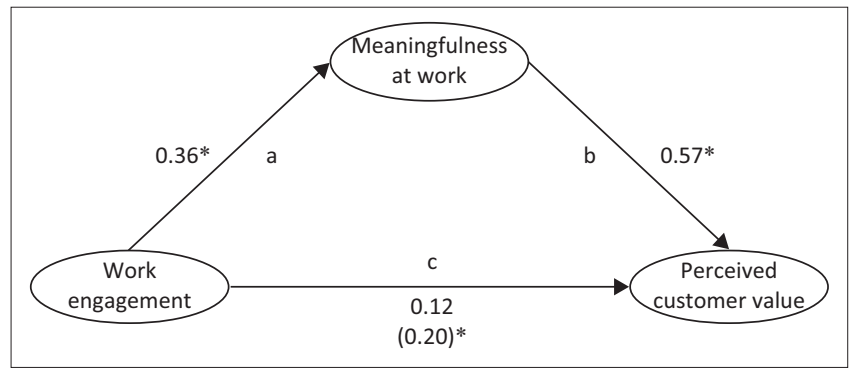

Notes: Value in parentheses represents the indirect effect of Work engagement via Meaningfulness at work on perceived customer value. BC: bias-corrected bootstrap approximation at $95 \%$ corrected confidence interval (two-sided). $N=152$. $^{*}$ Standardised path coefficients are significant at $p<0.05$.

FIGURE 2: Simple mediation model: Work engagement, meaningfulness at work and perceived customer value.
The correlation analysis revealed that work engagement and meaningfulness will be associated in the manufacturing organisation. The result implies that higher levels of work engagement would most probably also be associated with higher recordings of employees who find meaning at the workplace. The specific result is consistent with previous South African findings of work engagement being associated with meaningfulness through work (Geldenhuys et al. 2014; Van Zyl et al. 2010)

\section{Theoretical and managerial applications}

Literature findings indicate that perceived customer value is related to improved customer satisfaction (Han \& Xie 2019; Mbango \& Toerien 2019), including improved sales performance (Chakrabarty et al. 2010). The findings of this study indicate that meaningfulness at the workplace predicted improved perceived customer value. The findings further specify that having engaged employees is not enough, but that the manufacturing organisation also relies on creating meaning at work for employees in order to improve their perceptions of customer value. South African organisations wishing to improve indications of meaningfulness at work should direct their attention towards person-job fit, self-concept-job fit (Scroggins 2008), calling orientation, job design and co-worker relations (Fouché, Rothmann \& Van der Vyver 2017). The improvement of work engagement would not only be applicable to the employees' finding meaning at the workplace, but will also be extended to the customer with enhanced perceptions of customer value, which in return will improve employee productivity and organisational performance.

\section{Limitations}

Although the study has made valuable contributions towards work engagement, meaningfulness at work and literature on perceived customer value, it has limitations. A quantitative cross-sectional study restricts causation conclusions from the results and interpretation should be restricted to the sample. Common method bias will remain a reality when doing data-using surveys. In a future qualitative study it should be possible to confirm the influence on perceived customer value, and provide more comprehensive insight into this specific relationship.

Data were collected from only one manufacturing organisation and are, therefore, not representative of the industry. Future studies should expand data collection to include more manufacturing organisations in order to generalise results to the industry.

\section{Conclusion}

Theoretically, work engagement should enhance meaningfulness through and at work and also improve perceived customer value. The current South African empirical investigation found evidence that this conceptual relationship does indeed exist and, therefore, contributes towards the body of knowledge pertaining to work engagement, meaningfulness and perceived customer value. In the present study evidence was found that an improvement in work engagement may also result in an im- 
provement in meaningfulness at the workplace. Furthermore, meaningfulness through work was found to have a positive impact on perceived customer value. These findings indicate that work engagement is not sufficient to improve employees' perceived customer value but that conducive levels of meaningfulness at the work place is also required.

\section{Acknowledgements Competing interests}

The authors have declared that no competing interests exist.

\section{Authors' contributions}

All authors contributed equally to this work.

\section{Ethical considerations}

The North-West University research ethics committee where the study was registered, ensured that ethically acceptable practices were adhered to throughout the study (MSPBS16/02/16-01/04).

\section{Funding information}

This research received no specific grant from any funding agency in the public, commercial, or not-for-profit sectors.

\section{Data availability}

Data sharing is not applicable to this article as no new data were created or analysed in this study.

\section{Disclaimer}

The views and opinions expressed in this article are those of the authors and do not necessarily reflect the official policy or position of any affiliated agency of the authors.

\section{References}

Aguinis, H. \& Glavas, A., 2019, 'On corporate social responsibility, sensemaking, and the search for meaningfulness through work', Journal of Management 45(3), the search for meaningfulness through work', Journal
1057-1086. https://doi.org/10.1177/0149206317691575

Anderson, E.W., Fornell, C. \& Rust, R.T., 1997, 'Customer satisfaction, productivity, and profitability: Differences between goods and services', Marketing Science 16(2), 129-145. https://doi.org/10.1287/mksc.16.2.129

AON Hewitt, 2015, 2015 Trends in global employee engagement: Making engagement happen, Aon Hewitt, London.

Barari, M., Ross, M., Thaichon, S. \& Surachartkumtonkun, J., 2021, 'A meta-analysis of customer engagement behaviour', International Journal of Consumer Studies 45(4), 457-477. https://doi.org/10.1111/ijcs.12609

Barnes, D.C., Ponder, N.P. \& Hopkins, C.H., 2015, 'The impact of perceived customer delight on the frontline employee', Journal of Business Research 28(2), 433-441. https://doi.org/10.1016/j.jbusres.2014.06.005

Chakrabarty, S., Brown, G. \& Widing, R.E., 2010, 'The effects of perceived customer dependence on salesperson influence strategies', Journal of Personal Selling \& Sales Management 30(4), 327-342. https://doi.org/10.1016/j.jbusres.2014.06.005

Christian, M.S. \& Slaughter, J.E., 2007, 'Work engagement: A meta-analytic review and directions for research in an emerging area', Academy of Management 2007 Annual Meeting: Doing well by doing good, AOM 2007, viewed 13 May 2020, from https://journals.aom.org/doi/pdf/10.5465/ambpp.2007.26536346.

Cohen, J., 1988, Statistical power analysis for behavioural science, Erlbaum, Hillside, NJ.

D'Enbeau, S. \& Buzzanell, P., 2013, 'Explicating creativity and design: The nature and meaningfulness of work in mad men', Western Journal of Communication 77(1) 54-71. https://doi.org/10.1080/10570314.2012.742558

Fairlie, P., 2011, 'Meaningful work, employee engagement, and other key employee outcomes: Implications for human resource development', Advances in Developing Human Resources 13(4), 508-525. https://doi.org/10.1177/1523422311431679

Field, A., 2009, Discovering statistics using SPSS, 2nd edn., Sage, London.
Fouché, E., Rothmann, S. \& Van der Vyver, C., 2017, 'Antecedents and outcomes of meaningful work among school teachers', SA Journal of Industrial Psychology 43(1), 1-10. https://doi.org/10.4102/sajip.v43i0.1398

Geldenhuys, M., Laba, K. \& Venter, C.M., 2014, 'Meaningful work, work engagement and organisational commitment', SA' Journal of Industrial Psychology 40(1), 1-10. https://doi.org/10.4102/sajip.v40i1.1098

Hager, F.W., 2018, 'The links between meaningfulness of work, work-engagement and mental well-being', in DOKBAT 2018-14th Annual International Bata Conference for PhD Students and Young Researchers, vol. 14, pp. 76-94. Faculty of ty in Zlín, Zlín.

Hair, J.F., Black, W.C., Babin, B.J. \& Anderson, R.E., 2010, Multivariate data analysis. A global perspective, 7 th edn., Pearson, Boston, MA.

Han, Y. \& Xie, K., 2019, 'Determinants of customer perceived online shopping logistics service quality value: An empirical study from China', International Journal of Logistics Research and Applications 22(6), 614-637. https://doi.org/10.1080/136 75567.2018.151786

Hayes, A.F., 2017, Introduction to mediation, moderation, and conditional process analysis: A regression-based approach, Guilford Publications, New York, NY.

Hinkin, T.R., 1998, 'A brief tutorial on the development of measures for use in survey questionnaires', Organizational Research Methods 1(1), 104-121. https://doi. org/10.1177/109442819800100106

Holbeche, L. \& Springett, N., 2004, In search of meaning in the workplace, Roffey Park Institute, Horsham.

Hoole, C. \& Bonnema, J., 2015, 'Work engagement and meaningful work across generational cohorts', SA Journal of Human Resource Management 13(1), 1-11. https://doi.org/10.4102/sajhrm.v13i1.681

IBM Corp., 2019, IBM SPSS statistics for windows, Version 25.0, IBM Corp, Armonk, NY.

Joshi, R. \& Sodhi, J., 2011, 'Drivers of employee engagement in Indian organizations', The Indian Journal of Industrial Relations 47(1), 162-182.

Kahn, W., 1990, 'Psychological conditions of personal engagement and disengagement at work', Academy of Management Journal 33(4), 692-724. https://doi. org/10.5465/256287

Kumar, V. \& Pansari, A., 2016, 'Competitive advantage through engagement', Journa of Marketing Research 53(4), 497-514. https://doi.org/10.1509/jmr.15.0044

Leroi-Werelds, S., Streukens, S., Brady, M.K. \& Swinnen, G., 2014, 'Assessing the value of commonly used methods for measuring customer value: A multi-setting
empirical study', Journal of the Academy of Marketing Science 42, 430-451. https://doi.org/10.1007/s11747-013-0363-4

Leuschner, R., Charvet, F. \& Rogers, D.S., 2013, 'A meta-analysis of logistics customer service', Journal of Supply Chain Management 49(1), 47-63. https://doi. org/10.1111/jscm.12000

May, D.R., Gilson, R.L. \& Harter, L.M., 2004, 'The psychological conditions of meaningfulness, safety and availability and the engagement of the human spirit', Journal of Occupational and Organizational Psychology 77(1), 11-37. https://doi. org/10.1348/096317904322915892

Mbango, P. \& Toerien, D.F., 2019, 'The role of perceived value in promoting customer satisfaction: Antecedents and consequences, Cogent Social Sciences 5, 1-16. https://doi.org/10.1080/23311886.2019.1684229

Pallant, J., 2007, SPSS Survival manual. A step by step to data analysis using SPSS for windows, 7 th edn., McGraw-Hill, New York, NY.

Robinson, J.P., Shaver, P.R. \& Wrightsman, L.S., 1991, 'Criteria for scale selection and evaluation', in J.P. Robinson, P.R. Shaver \& L.S. Wrightsman (eds.), Measures of
personality and social psychological attitudes, pp. 1-16, Academic Press, San Diego, CA.

Rodell, J., 2013, 'Finding meaning through volunteering: Why do employees volunteer and what does it mean for their jobs?', Academy of Management Journal 56(5), 1274-1294. https://doi.org/10.5465/amj.2012.0611

Schaufeli, W.B., 2014, 'What is engagement?', in Employee engagement in theory and practice, C. Truss, K. Alfes, A. Shantz \& E. Soane (eds.), pp. 15-35, Routledge, London.

Schaufeli, W.B., Bakker, A.B. \& Salanova, M., 2006, 'The measurement of work engagement with a short questionnaire, Educational and Psychological Measurement 66(4), 701-716. https://doi.org/10.1177/0013164405282471

Scroggins, W.A., 2008, 'Antecedents and outcomes of experienced meaningful work: A person-job fit perspective', Journal of Business Inquiry 7, 68-78

Slater, S.F., 1997, 'Developing a customer value-based theory of the firm', Journal of the Academy of Marketing Science 25(2), 162-167. https://doi.org/10.1007/BF02894352

Steger, M.F. \& Dik, B.J., 2010, Work as meaning', in P.A. Linley, S. Harrington \& N. Page (eds.), Oxford handbook of positive psychology and work, pp. 131-142, Oxford University Press, Oxford.

Tabachnick, B.G. \& Fidell, L.S., 2007, Using multivariate statistics, 5th edn., Allyn and Bacon, New York, NY

Van de Schoot, R., Lugtig, P. \& Hox, J., 2012, 'A checklist for testing measurement invariance', European Journal of Development Psychology 9(4), 486-492. https:// doi.org/10.1080/17405629.2012.686740

Van Zyl, L.E., Deacon, E. \& Rothmann, S., 2010, 'Towards happiness: Experiences of work-role fit, meaningfulness and work engagement of industrial/organisational psychologists in South Africa', SA Journal of Industrial Psychology 36(1), 1-10. https://doi.org/10.4102/sajip.v36i1.890

Wang, J. \& Wang, X., 2012, Structural equation modelling: Applications using Mplus, John Wiley \& Sons, Chichester UK

Watson, T., 2012, Towers Watson Global Workforce Study, viewed n.d. from www. towerswatson.com.

Williamson, J.C. \& Geldenhuys, M., 2014, 'Positive work experiences and life satisfaction: The moderating role of gender', Journal of Psychology in Africa 24(4), 315-320. https://doi.org/10.1080/14330237.2014.980619

Zhao, X., Lynch, J.G. \& Chen, Q., 2010, 'Reconsidering Barron and Kenny: Myths and truths about mediation analysis', Journal of Consumer Research 37(2), 197-206. https://doi.org/10.1086/651257 